\title{
The Effects of Motivational/Reward System and a Spelling Racetrack on Spelling Performance in General Education: A Case Report
}

\author{
Maighain Arkoosh, Kimberly P. Weber and T.F. McLaughlin*
}

Department of Special Education, Gonzaga University, 502 East Boone Avenue, Spokane, WA 99258-0102, USA

\begin{abstract}
The purpose of this study employ and evaluate the use of a spelling racetrack with a single general education student with low performance in spelling. Our participant was a 7-year-old-student having difficulty spelling words from the general education curriculum. The study was conducted in a general education classroom in a large urban school in eastern Washington. The two dependent variables were the number of correct and error words from his spelling tests each day. The effects of the spelling racetracks procedure and its addition within an ongoing motivational system in the classroom were evaluated using an $\mathrm{ABAB}$ single case replication design. When the spelling racetrack was being employed the participant's number of correct words spelled increased while his errors declined. This was replicated each time it was in effect. We also found a statistically significant increased for correct words and a significant decline in errors. The benefits of employing a racetrack procedure that could be modified for spelling was both effective and motivating for the participant are presented. The limitations of the present case report are also outlined.
\end{abstract}

With the modern conveniences of email and text messaging, the art of spelling may have been lost in a hurried realm of shorthand and best guesses [1]. Although the necessity of correct spelling may appear to be less of a priority today, in reality, it remains the writing convention valued highest by society $[2,3]$. Not only does spelling impact a child's clarity of expression in writing, but it can influence another person's perceptions concerning the child's competence in writing [4].

Reading is another central area of academic importance affected by a person's inability to spell. Learning the connection between graphemes and phonemes used to spell words aids in the acquisition of reading-related processes [1]. The very nature and development of reading is supported through spelling instruction [5].

Given the need to learn spelling in activities that span from reading to writing official documents $[1,3]$ to the ability to express oneself with clarity [4], the importance of effective and efficient spelling instruction remains very important in today's schools. When considering which spelling approach to employ to assist students, one area to consider is the ease and practicality with which the spelling program can be used in a classroom where multi-level learners are present [3-5]. The other being, the empirical evidence that has been gathered to support its use in the classroom [3].

Self-concept and motivation may also play a role in a student's academic performance in spelling [6]. Students atrisk of language difficulties have been reported to have lower perceptions of control, lower belief strength, outcome evaluation, and normative beliefs about themselves [6].

\footnotetext{
*Address correspondence to this author at the Department of Special Education, Gonzaga University, 502 East Boone Avenue, Spokane, WA 992580102, USA; Tel: +509 313 3508; Fax: 509313 5965;

E-mail: tim.mclaughlin6@comcast.net,mclaughlin@gonzaga.edu
}

Given the possibility of a low self-concept due to struggling academic achievement, motivation becomes a key factor in instructing such students [6]. There is a very large and diverse literature regarding how to improve student selfconcept. The literature from the largest experiment in compensatory education that took place in the 1960's through the 1970 's reported that students who were taught using behavioral contingencies with explicit instruction for both academic and social behavior had higher self-concepts that those taught in programs whose primary aim was to improve their self-concept [7-9]. Motivating our participant with low academic achievement was hypothesized to improve his performance. In addition, other research suggests that allowing responses that require minimal time and effort may be seen as more "acceptable" by students at risk for school failure $[10,11]$. There wealth of evidence in the behavioral literature that improving academic skills increases student selfconcept [7-9]. Finally, behavioral psychology has a welldocumented date base as to the effectiveness of motivational systems on student performance $[12,13]$. To assist our participant, a motivational (sticker) system was put into place.

The use of a racetrack type procedure has been documented in the literature $[14,15]$. Briefly, this procedure is employing a racetrack format to teach specific items that students need to learn. The racetrack is composed of 28 boxes that are arranged like an oval track on a piece of paper. There are two racecars and a flag on each track [15]. Racetracks have been used to improve sight word vocabulary [1518] and for teaching basic math facts [19].

The purpose of this study was to examine the effects of a motivational/reward system in conjunction with a spelling racetrack on typically developing second grader to learn spelling words derived from the general education classroom instruction. We hypothesized that the intervention, which incorporated drill and practice as well as a motivational system, would allow the student to reach mastery in spelling. 


\section{METHOD}

\section{Participant and Setting}

The participant for this study was a typically developing, seven-year-old male enrolled in a general education, second grade classroom. However, his classroom teacher has observed an extreme lack of educational motivation, which had become apparent in his academic achievement. According to his teacher, he often required consistent praise and encouragement to achieve minimal productivity in school. Despite constant efforts on behalf of his classroom teacher, he did not spend any time outside the classroom on homework or study. This study took place in one of the three empty classrooms in the participant's elementary school. Each student had his or her own desk and chair.

\section{Materials}

Materials needed for this study included pre-prepared spelling racetracks, blank lined paper for spelling tests, and pencils. The student had his own racetrack book where they placed stickers. The first author employed a data collection form to record the results of this study and to determine reliability measurement. The spelling racetrack was modeled after that we have developed for reading $[15,16]$, and math [19]. For spelling, words are placed on racetrack forms and the child is to spell words orally as he moves around the racetrack from left to right [20].

\section{Motivational System}

A sticker motivational system was put into effect for the whole experiment. Students earned stickers for appropriate hallway behavior, working hard on academic tasks, etc. The motivational system was in effect for both baseline and the spelling racetracks conditions. During the spelling racetracks condition, our participant still earned stickers for completing his spelling racetracks, appropriate hallway behavior, and compliance. The only difference being that completing his racetracks was added to the sticker system. Once the spelling racetrack was filled with stickers, he exchanged his completed racetrack for a mini-car. Mini cars had been determined to be an effective reward during a forced-choice preference assessment carried out by the first author [12].

\section{Dependent Variable}

The first dependent variable for this study was the number of words spelled correctly. Correct words were defined as written responses that completely matched the spelling of the words on the master list. All words on the master lists were spelled in accordance to Webster's Dictionary. The second dependent variable was the number of errors. An incorrect word was defined as any written response that did not exactly match the spelling of the word on the master lists.

\section{Data Collection and Interobserver Agreement}

After each spelling test was completed, the first author corrected the tests by comparing the student spelling to that on the master lists. Incorrect words were marked with a slash or a check. The number of corrects over errors were recorded at the top of the paper. The date, session number, the number of words correct or incorrect, and the percentage correct were also recorded on the data collection form. After the first author regraded and recorded his score from the tests, a secondary observer then corrected the tests again by comparing the participant's spelling of his words to that on the master list. The participant's spelling list was copied so the second observer could not use the first author's scoring. The second observer recorded the number correct over the number incorrect on the top of the copied spelling test. On this separate data collection sheet, the secondary observer also placed the date, session number, number correct, number incorrect, and percent correct.

Interobserver reliability data were collected for $100 \%$ of the sessions. The number correct and errors was compared. An agreement was defined as both observers scoring the word in the same manner. Any deviation in scoring was scored as a disagreement. Agreements and/or disagreements were made on a word-by-word basis. Reliability was calculated by dividing the number of agreements by agreements plus disagreements and multiplying by $100[12,13]$. The intergrader agreement was $99.7 \%$.

\section{Experiment Design and Conditions}

This case report employed an ABAB single-subject design [20] to compare the use of a spelling racetrack with its daily self-practice procedures to that typically employed during traditional spelling instruction. One week of baseline (A) was followed by two weeks of intervention (B), a return to baseline (A) for one week, and then a final week of the spelling racetrack procedure (B).

Baseline. The study began with the first author taking data for three baseline sessions. Baseline consisted of independent study and a sticker reward system. During baseline, no additional instruction was provided during baseline. However, the typical spelling instruction in the general education setting remained. The participant was also asked to independently to study his words at home. One test was given each day of baseline. The participant also received stickers for appropriate hallway behavior, completing the tests, and overall compliance. Once the student filled his racetrack with stickers, he earned a mini-car.

Spelling racetrack. During the first phase of a session, the student took a test over the week's words (with the exception of the first day of each week, when only a racetrack was administered). The student then completed two or three spelling racetracks. The number of words on the pretest determined the number of racetracks completed by the student during each week of the intervention. Each incorrect word was followed by two or three mastered words on the spelling racetrack. The first author timed the student as he spelled the words on the racetrack. This was done to encourage our participant to improve on his score from the previous racetrack. Student was encouraged to beat his previous scores throughout the spelling racetrack intervention. Finally, the participant was also required to write each of the misspelled words three times on the racetrack paper before being allowed to complete the next spelling racetrack. Just as in baseline, the participant could earn stickers for his racetrack sticker books for appropriate hallway behavior, completing the racetracks and tests, and compliance. 


\section{RESULTS}

During the first baseline, the participant's spelling performance was poor. His correct averaged $(M=1.0$; range 1 to 3 corrects). Like wise his errors were high ( $M=11$; range 10 to 11$)$. When the spelling racetrack procedures were first implemented, his correct spelling increased $(M=10.33$; range 5 to 11). The participant's errors decreased $(M=$ 1.667; range 1 to 3 ). During the second baseline his corrects decreased $(M=2.33$; range $=1$ to 4$)$, while his errors increased $(M=9.667$; range 8 to 11$)$. During the final racetracks intervention, the participants spelling performance increased for corrects for both baselines $(M=6.33$; range 4 to 12$)$. A decline in errors was also found $(M=5.667$; range 0 to 8 ).

A repeated analysis of variance was calculated for both corrects and errors. Significant differences were found for treatment for corrects $(F=32 ; d f=3 ; p=.0004)$ and errors $(F=26 ; d f=3 ; p=.001)$. Follow up tests using a Scheffe's $F$ test found significant differences for corrects and for errors except for the initial baseline and the last baseline.

\section{DISCUSSION}

The student's results confirmed our hypothesis. That the spelling racetrack and its small addition to the motivational system already in place during baseline, would increase his spelling performance. This was noted each time that the spelling racetrack was in effect.

There were several strengths in the present case report. First, the participant was very compliant when he completed all the experimental conditions used the research. Our participant worked diligently for the possibility of earning a mini-car and engaged in little inappropriate behavior occurred throughout data collection. Another positive aspect of this case report was its low cost. The only costs incurred were those to copy racetracks and data, and to purchase the mini-cars for reward. All of this was estimated to cost less than $\$ 5.00$. The results did produce a cause and effect relationship between a motivational system and the spelling racetrack procedures. Both his corrects improved while his errors declined. By providing the student with a competitive way to learn and practice his spelling words, he eagerly engaged in the spelling activity. In the past, he normally avoided such work in the classroom. He also told the first author that he really enjoyed the spelling racetrack procedure. We have found this to be the case in our earlier research [14-19] with reading racetrack procedures.

The limitations of the present case report were several. First, the motivational system was combined with the spelling racetrack procedure. Therefore, the individual contribution of the motivational sticker system to the spelling racetrack cannot be clearly determined. This issue will have to be examined in future research. However, we have presented some anecdotal evidence regarding the motivational properties of the reading racetracks procedures [17-19] and in this paper during the spelling racetrack phases. Another limitation was the short time span for data collection. Due to the ending of the first author's practicum, data collection was halted. Also, having data collection last longer, would have added confidence that the outcomes were not due to chance or novelty. However, as Kazdin [21] has presented, the use of the $\mathrm{ABAB}$ design does allow for a functional relationship between the use of the intervention and improved outcomes to be determined. However, when employing academic responding, the behavior may not return to previous baseline levels $[12,13,21]$. However, we did not find such an outcome in our descriptive outcomes or statistical comparisons.

The use of a permanent product data (spelling exams and worksheets) as the dependent measure made carrying out reliability of measurement quite straight forward. The second observer could grade the participant's work that same day or later. The use of the second observer required little training or additional time. All the second observer was required to do was to score the participant's spelling. No information regarding the possible outcomes of the research was provided to the second observer. The use of permanent product data collection has been urged by several individuals when carrying out classroom action research [12, 13, 22]. Finally, we were able to add to the growing list of spelling interventions $[3,4,10,11]$ that have been verified in actual classroom research.

The outcomes provide the first example of employing and extending a racetracks procedure in spelling. Also, it we employed a student enrolled in general education. Our previous research [14-20] has typically involved teaching either reading or math for students in special education. Additional research could consist of implementing the procedure on a class-wide basis to see if the results generalize to a large group setting. Research could also include a more studentdirected approach where they create and/or correct their own racetracks. Such a self-managed approach called cover, copy, and compare has been employed with a wide range of students and $[12,13]$. The combining of these two approaches may provide a very fruitful area of action research in the classroom.

\section{ACKNOWLEDGEMENTS}

Preparation of this document was in partial fulfillment of the requirements for EDSE 465 -Classroom Management and EDSE 410 -Precision Teaching for Teacher Certification and Endorsement in Special and Elementary Education. Requests for Reprints maybe obtained from Kimberly Weber, Professor, Department of Special Education, Gonzaga University, Spokane, WA 99258-0025. Maighain Arkoosh is now teaching special education in the Vancouver Public Schools, Vancouver, WA. A copy of the spelling racetrack can be obtained from the third author via email: mclaughlin@gonzaga.edu.

\section{REFERENCES}

[1] Bos M, Reitsma P. Experienced teachers' expectations about the potential effectiveness of spelling exercises. Ann of Dyslexia 2003; 53: 104-27.

[2] Beckham-Hungler D, Williams C. Teaching words that students misspell: spelling instruction and young children's. Writ Lang Arts 2003; 80: 299-309.

[3] McLaughlin TF, Weber KP, Barretto A. Spelling: academic interventions. In: Watson TS, Skinner CS, Eds. Encyclopedia of School Psychology. New York: Kluwer Academic/Plenum Publishers 2004; pp. 317-20.

[4] Graham S, Harris KR, Funk-Chorzempa B. Extra spelling instruction: promoting better spelling, writing, and reading performance right from the start. Teach Except Child 2003; 35(6): 66-8. 
[5] Templeton S. Spelling: best ideas = best practices. Voice Mid 2003; 10(4): 48-9.

[6] Sideridis GD. Goal importance and students at risk of having language difficulties: An under explored aspect of student motivation. J Learn Dis 2002; 35: 343-56.

[7] Becker WC, Engelmann S. Sponsor findings from project follow through. Eff Sch Pract 1997; 15(1): 2-5.

[8] Bushell D. An engineering approach to the elementary classroom: The Behavior Analysis Follow-Through project. In: Catania AC, Brigham TA, Eds. Handbook of applied behavior analysis. New York: Irvington Publishers 1978; pp. 525-63.

[9] Becker WC, Carnine D. Direct instruction: A behavior theory model for comprehensive educational intervention with the disadvantaged. In: Bijou SW, Ruiz R, Eds. Behavior modification: contributions to education. Hillsdale, NJ: Lawrence Erlbaum 1981; pp. $145-210$.

[10] McLaughlin TF, Skinner CH. Improving academic performance through self-management: Cover, copy, and compare. Intervent Sch Clin 1996; 32: 113-18.

[11] Skinner CH, McLaughlin TF, Logan, P. Cover, copy, and compare: a self-managed academic intervention across skills, students, and settings. J Behav Educ 1997; 7: 295-306.

[12] Alberto P, Troutman AC. Applied behavior analysis for teachers. $8^{\text {th }}$ ed. Upper Saddle River, NJ: Merrill/Prentice-Hall 2008.

[13] Copper JO, Heward WL, Heron T. Applied behavior analysis. $2^{\text {nd }}$ ed. Upper Saddle River, NJ: Merrill/Prentice-Hall 2008.
[14] Rinaldi L, McLaughlin TF. The effects of reading racetracks on the fluency of see-to-say words in isolation by a student with learning disabilities. J Prec Teach Cel 1996; 13(2): 44-52.

[15] Rinaldi L, Sells D, McLaughlin TF. The effects of reading racetracks on the sight word acquisition and fluency of elementary students. J Behav Educ 1997; 7: 219-33.

[16] Anthony C, Rinaldi 1, Hern C, McLaughlin TF. Reading racetracks: A direct replication and analysis with three elementary students. $\mathrm{J}$ Prec Teach Cel 1997; 14(2): 31-6.

[17] Falk M, Band M, McLaughlin TF. The effects of reading racetracks and flashcards on sight word vocabulary of three third grade students with a specific learning disability: A further replication and analysis. Int J Spec Educ 2003; 18(2): 51-7.

[18] Printz K, McLaughlin TF, Band M. The effects of reading racetracks and flashcards on sight word vocabulary: A case report and replication. Int J Spec Educ 2006; 21(1): 103-8.

[19] Beveridge B, Weber KP, Derby KM, McLaughlin TF. The effects of a math racetrack with two elementary students with learning disabilities. Int J Sp Educ 2005; 20(2): 58-65.

[20] Alexander CL, McLaughlin TF, Derby KM, Cartmell H. The effects of reading racetracks on sight words across four elementary students with differing disabilities. Open Rehab J 2008; 1: 47-52.

[21] Kazdin AE. Single case research designs: Methods for clinical and applies settings. New York: Oxford University Press 1982.

[22] McLaughlin TF. An analysis and evaluation of educator selected data collection procedures in actual school settings: a brief report. Child Fam Behav Ther 1993; 15(2): 61-64.

(C) Arkoosh et al.; Licensee Bentham Open.

This is an open access article licensed under the terms of the Creative Commons Attribution Non-Commercial License (http://creativecommons.org/licenses/by$\mathrm{nc} / 3.0 /$ ) which permits unrestricted, non-commercial use, distribution and reproduction in any medium, provided the work is properly cited. 